\title{
Comparative study of refractive errors in West Malaysia
}

\author{
S. GHANDRAN
}

Department of Ophthalmology, University Hospital, Kuala Lumpur, Malaysia

In West Malaysia, there are three major ethnic groups, Malays, Chinese, and South $\frac{D}{0}$. Indians. Interesting features emerge when the refractive errors of the Malaysians, as aco whole and as separate ethnic entities, are compared with the Caucasians.

\section{Methods and material}

This is a study of 750 cases $(1,500$ eyes) which were refracted at the Eye Clinic of University Hospital, Kuala Lumpur, Malaysia, during a 4-year period (1967 to 1970). All cases in which a refraction was undertaken as part of a routine investigation, whether the patients complained of visual loss $\overline{\$}$ or not, are included in this series. This is therefore a non-visually selected sample but not a random $\vec{\theta}$ selection from the general population. They belonged to one of the three main ethnic groups:N 223 Malays, 292 Chinese, and 235 Indians. Minor groupings, which accounted for 2 per cent. of the cases, were excluded from this study. The ages ranged from 5 to 65 years. The data for thoses above 65 years of age are less valid because they may be associated with pathological conditions (Chandran and Ooi Eu-Sen, 1971). Cycloplegia was routinely used in children under the age of Io years, in cases of hypermetropia, and in difficult cases of refraction. Only the refractive erroro and not the final prescription is used in this study. The vision had to be capable of improvement to $\overrightarrow{\vec{O}}$ at least $6 / 9$ to be included in this series.

\section{Results}

Table I shows the percentage distribution of refractive errors in the series as a whole, compared with Sorsby's Caucasian series (Sorsby, Benjamin, Davey, Sheridan, and․ㅡ. Tanner, 1957; Sorsby, Sheridan, Leary, and Benjamin, 1960). The Malaysian series is further subdivided into two classes:

(a) Those showing mainly spherical error, any astigmatism being $0.5 \mathrm{D}$ or less;

(b) Those showing astigmatic error of $0.6 \mathrm{D}$ or more, with or without spherical errors. Since class $a$, containing 77.5 per cent., showed essentially the same distribution as the ज series as a whole, all the comparative studies are treated as a whole. The Caucasian $\mathbb{O}^{\circ}$ range varies from + io to - I I $\mathrm{D}$, with a peak on the hypermetropic side, o to $+2 \mathrm{D}_{\mathrm{C}}^{N}$ accounting for 73.4 per cent. The Malaysian range varies from +5 to $-20 \mathrm{D}$, with a? peak on the myopic side, o to $-2 \mathrm{D}$ accounting for 39.5 per cent. Figs $\mathrm{I}$ and 2 illustrate the features of Table I (opposite).

Table II (overleaf) shows the Malaysian eyes subdivided into the three ethnic groups. The Ghinese and Malays show a peak between o and $-2 \mathrm{D}$, accounting for 40.3 and $39^{\circ} 0$ per cent. respectively, whereas a hypermetropic distribution between o and $+2 \mathrm{D} \stackrel{\mathbb{D}}{\mathbb{D}}$ accounts for $19^{\circ} 0$ and $23^{\circ} 1$ per cent.

For the Indians the peak is more of a plateau, +2 to $-2 \mathrm{D}$, the hypermetropic peak being $34 \cdot 7$ per cent. and the myopic peak 37 per cent. 
Table I Percentage distribution of ocular refraction (peaks boxed)

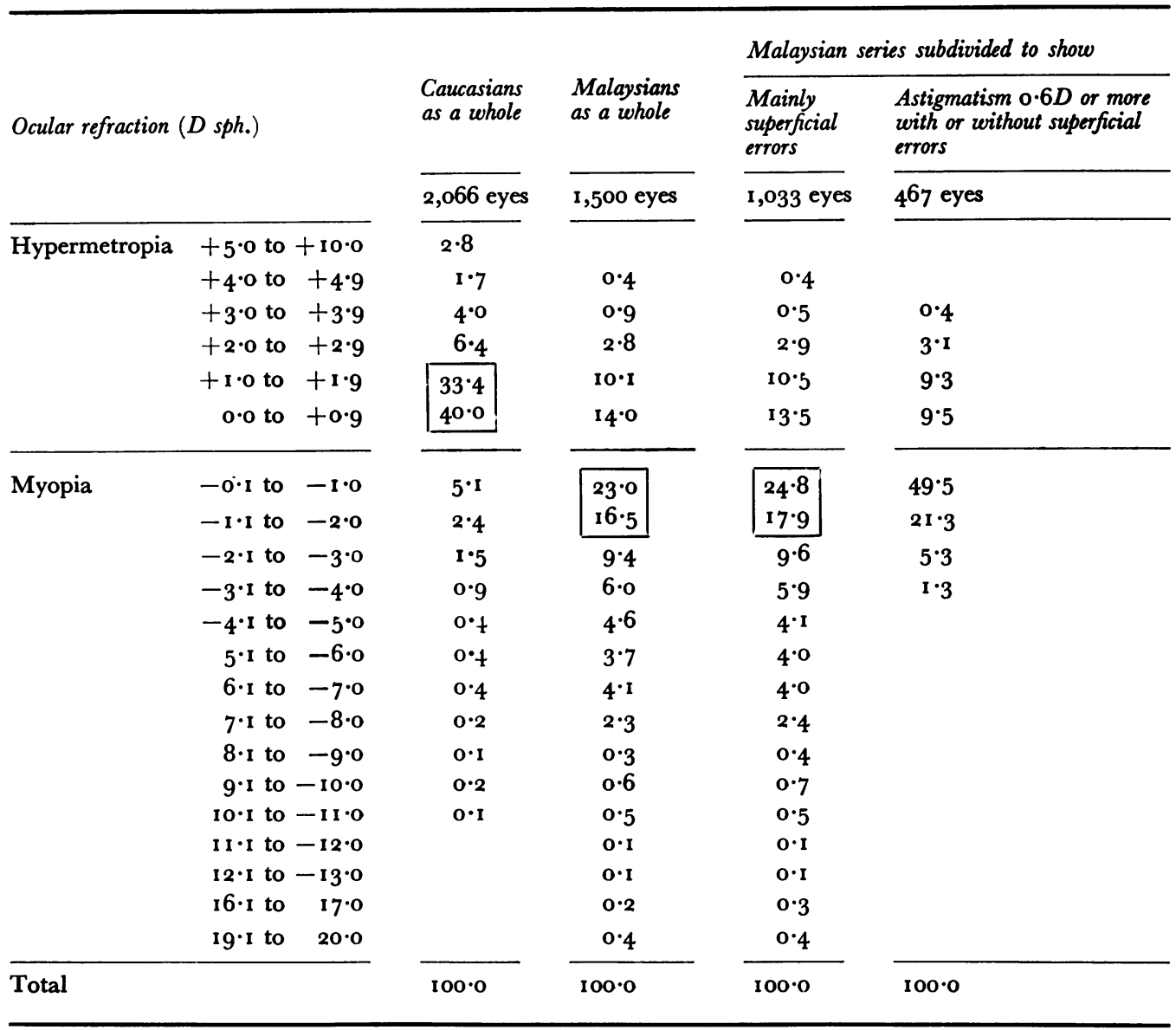

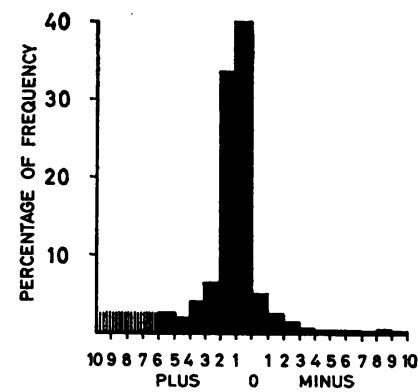

FI G. I Distribution of refraction in Caucasian series

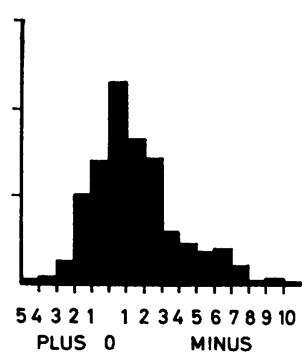

FIG. 2 Distribution of refraction in whole Malaysian series

Figs 3 to 5 (overleaf) illustrate these features, the Chinese showing the greatest shift to the right, and the Indians the least shift, compared with the Caucasian series.

Table III (overleaf) compares the total ratio of hypermetropia to myopia in each group to the nearest whole number. The Caucasians show the greatest ratio with 88:12 and the Malaysians 28:78 (Chinese 21:79, Malays 27:73, Indians $39: 6$ I). 
Table II Comparative distribution of ocular refraction in the three ethnic groups (peaks boxed)

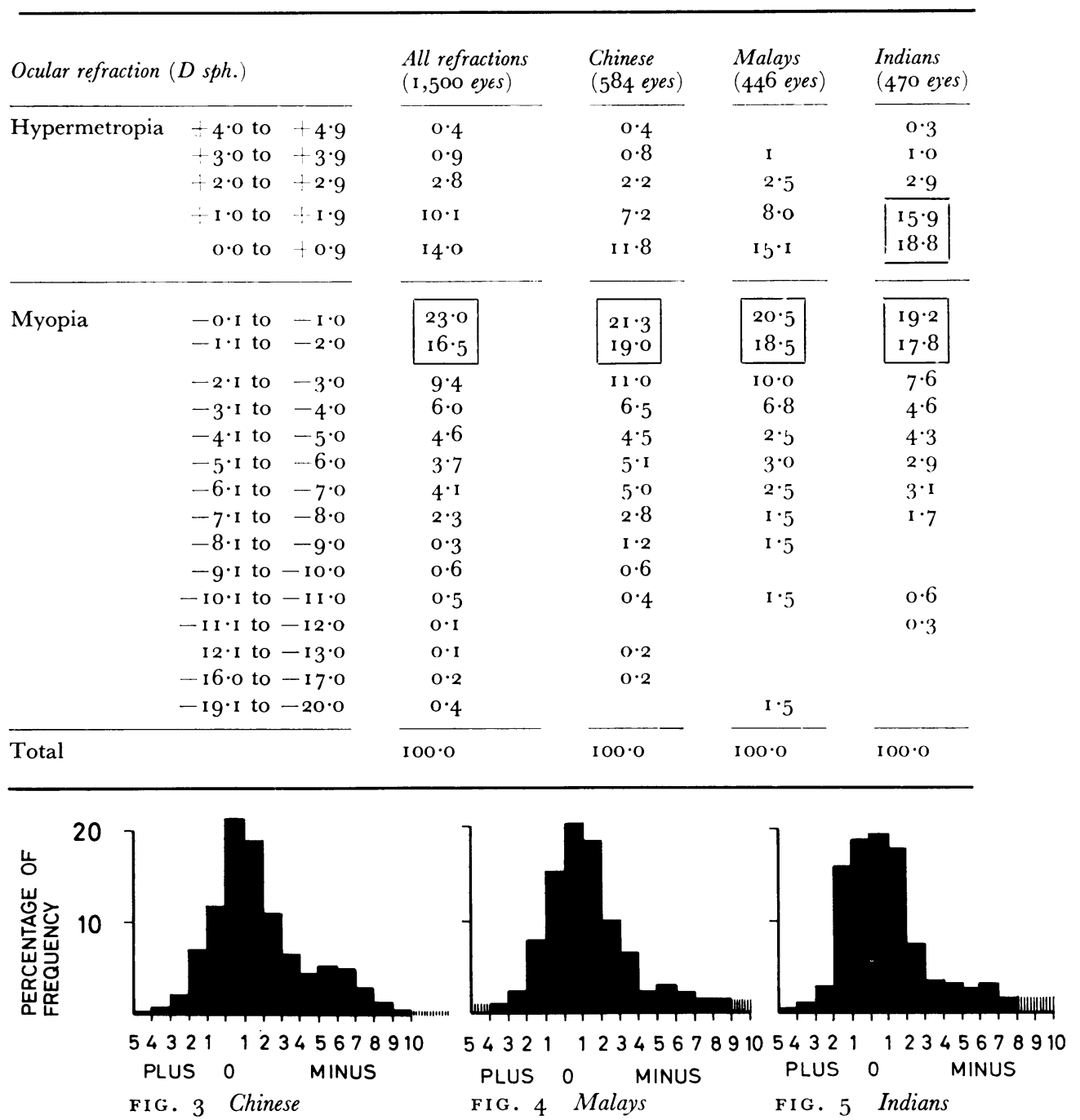

Table III Ratio of hypermetropia to myopia (to the nearest whole number)

\begin{tabular}{|c|c|c|}
\hline Group & Hypermetropia & Myopia \\
\hline Caucasians & 88 & I 2 \\
\hline $\begin{array}{l}\text { Malaysians } \\
\text { (as a whole) }\end{array}$ & 28 & 72 \\
\hline Chinese & 21 & 79 \\
\hline Malays & 27 & 73 \\
\hline Indians & 39 & $6 I$ \\
\hline
\end{tabular}




\section{Discussion}

Marked differences are seen when Caucasian eyes (Fig. I) are compared with Malaysian eyes (Fig. 2).

In Fig. I hypermetropia predominates, a peak between o and + I D accounting for 40 per cent. and between $+\mathrm{I} \cdot \mathrm{I}$ and $2 \mathrm{D}$ for 33.4 per cent. The total ratio of hypermetropia to myopia is 88 to 12.

In Fig. 2 myopia predominates, a peak of $-0 \cdot 1$ to $-\mathrm{I} \mathrm{D} \mathrm{accounting} \mathrm{for} 23.0$ per cent. and a peak of $-I \cdot I$ to $-2 \mathrm{D}$ for $\mathrm{I} 6 \cdot 5$ per cent.; the fall on the hypermetropic side is sharp, with a generous myopic tail to the right. The total ratio of hypermetropia to myopia is 28 to 72 .

Even the ranges show significant differences; in the Caucasians it varies from + Io to - I I D and in the Malaysians from +5 to $-20 \mathrm{D}$. Thus the series shows that the Malaysian population as a whole has an excess of myopia. The development of I D of myopia, unlike hypermetropia, would rapidly attract attention, so that this series could have a slight myopic bias (unlike Sorsby's non-selective series). Even so, the shift of the peak to the right, with a generous myopic distribution, is significant compared with the findings in Caucasians.

When the three ethnic groupings are studied (Table II, Figs 3 to 5), the average myopia in Chinese is 79 per cent., Malays 73 per cent., and Indians 6 I per cent. The peaks in all three groups show a shift to the right with a generous myopic tail, which is most marked in the Chinese and least in the Indians, in whom the peak is more of a plateau on either side of $o(+2$ to $-2 \mathrm{D})$. The Malays are more like the Chinese and both Chinese and Malays also show a sharp fall on the hypermetropic side, whereas in the Indians the fall is more gradual.

The myopia will usually reach a predetermined degree, its extent being decided largely by heredity (Duke-Elder and Abrams, 1970) and possibly by race.

\section{Summary}

The refractive state of 1,500 Malaysian eyes in the three major ethnic groups (Malays, Chinese, and South Indians) is compared with Sorsby's Caucasian series. The Malaysians show an excess of myopia -72 per cent. with the shift of the peak to the myopic side (o to $-2 \mathrm{D}$ ). The slope on the hypermetropic side is sharp and that on the myopic side gradual. These features are most marked in the Chinese and least marked in the Indians. The racial distribution of the refractive errors is discussed.

I wish to thank the Department of Medical Illustration, University of Malaya, for the figures and Miss Yap Tse Chin for assisting in the preparation of this paper.

\section{References}

CHANDran, s., and ool eU-SEn, v. (1971) Med. F. Malaya, 25, p. 193

DUKE-ELDER, S., and ABRAMS, D. (1970) "System of Ophthalmology", vol. 5, "Ophthalmic Optics and Refraction", p. 268. Kimpton, London

SORSBy, A., Benjamin, B., DAVEY, J. B., SHERIDAN, M., and taNNER, J. M. (1957) "Emmetropia and its Aberrations". Spec. Rep. Ser. med. Res. Coun. (Lond.), No. 293, p. 17

-, sheridan, M., Leary, G. A., and benjamin, B. (1960) Brit. med. F., x, 1394 